Resumo

Nossa proposta tem início na tentativa de circunscrever a definição do mito para Freud, mostrando suas frutiferas teorizacões sobre a estrutura das sagas para a práxis analitica. À luz, sobretudo, de Moisés e o Monoteísmo e de Totem e Tabu, seguimos nosso objetivo de mostrar que o mito ocupa um lugar de destaque no campo psicanalítico, e que as vias da obra de Frend nos levaram à conclusão de que o fundador da psicanálise termina por valorizar o modelo das histórias miticas retrabalhadas pela psicanálise numa interseção com a sua própria concepção de verdade bistórica.

Descritores: mito; psicanálise; antropologia; verdade bistórica.

\section{MITO E VERDADE EM FREUD: COMO SE CONSTRÓI UMA CLINICA}

\author{
Aline Vieira Fridman
}

\section{Introdução}

Y este artigo, examinaremos a conexão entre o mito e a conceitualização da verdade histórica (die historische Warbreit, Freud, 1939/2004a, p. 123) sugerida em trechos bastante oportunos da obra de Freud. Ainda que não seja nosso objetivo sustentar que ele tenha assimilado os efeitos da verdade mítica à noção de verdade psicanalítica, não se deve ler tão prontamente como uma oposição o que caracteriza a relação que intentamos estabelecer entre elas. Levando em conta a proposta acima, refletimos sobre os motivos de Freud para trabalhar com a narrativa mítica em sua elaboração teórica e em suas intervenções de tratamento, e a possibilidade de articular a ficção mítica e o método psicanalítico. Para orien-

Psicóloga clínica. Mestra e Doutoranda em Teoria Psicanalítica pelo Programa de Pós-Graduação em Teoria Psicanalítica do Instituto de Psicologia da Universidade Federal do Rio de Janeiro-PPGT-IP/UFRJ. 
tarmos questionamentos e indicarmos novas indagações, partiremos de "Moisés e o monoteísmo" (Freud, 1939/2004a), fazendo um recorte na história de Moisés, tal como abordada por Freud.

Essa personagem fundamental no Judaísmo protagoniza as indagações freudianas de então (1934-1938) na busca pela verdade sobre as origens. Introduziremos o leitor na complexa trama do livro de Freud para atingir a interlocução entre as categorias de verdade histórica e de mito a que Freud deu lugar. Presumimos haver um encontro do relato mítico com a verdade quando o seu autor encontra no mito um fragmento - um resto - de verdade (Lemérer, 1997; Lo Bianco \& Araujo, 2007).

Esse achado das investigações de Freud não tem o mesmo valor que "a segurança ilusória que advinha da história puramente factual do século XIX" (Carr, 1961/2002, p. 63), tradição fundada no apelo desmesurado aos documentos e consistindo em grandes agrupamentos de fatos irrefutáveis - pois documentados. É relevante tocar aqui na obstinação dos historiadores positivistas em restabelecer o passado como de fato aconteceu (Ranke, 1830, citado por Carr, 1961/ 2002 , p. 45), para opô-la ao trabalho que Freud, por sua vez, faz com os eventos que recolhe.

No culto positivista ao fato, seus expoentes pregavam o apagamento da subjetividade do historiador, ele próprio subtraído como autor, mera consciência receptora de dados independentes dela (Carr, 1961/2002). Acreditando que afirmar a história como ciência só seria possível com o uso de fatos de verificação segura, esse modelo-representado por Ranke, Langlois e Seignobos - desconsidera que os fatos históricos são na verdade uma série de "julgamentos aceitos" (Barraclough, 1955, citado por Carr, $1961 / 2002$, p. 50) e que se tornam fatos na medida em que são eleitos como tais pelo historiador1

Sabemos o quanto essa vertente, que distingue fatos puros e interpretações, sujeito e objeto do conhecimento, receberá críticas internas à sua disciplina, sobretudo pelas marcantes teses da École des Annales, nos anos $1930^{2}$, que imbuída dos métodos das ciências sociais, recusava a hipótese de tempo linear e irreversível, enfatizando o aspecto repetitivo e insistente dos fenômenos humanos (Bloch, 1949/2001; Le Goff, 2002). No texto de Bloch (1949/2001, pp. 95-6), lemos a defesa de um método e de uma história avessa a todo tipo de certeza quanto ao passado, dando lugar no exercício do historiador - um homem inseparável do seu tempo ao presente como solo das reflexões e da construção dos fatos passados para a história (Bloch, 1949/2001, p. 60).

Contudo, à nossa discussão interessa o contraponto das ideias de Freud (1918/2004b,1939/2004a) a essa postura dita imparcial do positivismo que define a função do histo- 
riador e o que são os fatos. Sua verdade bistórica é constituída pela implicação do sujeito no seu relato ao analista, do qual pode emergir, como efeito de sua fala, o que vem a ser sua história (Lacan,1966).

A Psicanálise se volta, entretanto para alguns eventos, excluídos de uma fixação textual e de uma problematização conceitual (Lemérer, 1997), postos à margem por contrariarem as intenções da tradição dominante ou pouco relevantes na formulação de uma ciência. O conteúdo dessas experiências recusadas se estabelece como desfigurações nas narrativas - míticas e científicas - e nelas Freud (1939/2004a) encontra fósseis de referência que o reenviam a uma verdade recalcada.

\section{Mito e verdade na história de Molsés}

Sem ignorar as referências à verdade e ao mito anteriores a 1939, é em "Moisés e o monoteísmo" (Freud, 1939/2004a) onde reconhecemos o ápice da relação entre esses dois pontos essenciais. Neles Freud (1939/2004a) afirma que não são irrefutáveis as circunstâncias que ele organizara em "um edifício de conjecturas" (p. 30) históricas. Entretanto suas dúvidas não o impedem de sustentar que Moisés, legislador e fundador do judaísmo, fora um inflamado membro da casta real egípcia que tomara para si a missão de perpetuar a nova religião após a morte de Akhenaton e a restauração do politeísmo (Freud, 1939/2004a).

Como governador de uma província fronteiriça do reino, Moisés teria se deparado com uma tribo semita imigrante, a quem escolhera para transmitir o monoteísmo de Aton, e com quem partira do império durante o período anárquico que sucedeu a morte do faraó herege. Em seguida, valendo-se de um costume egípcio, Moisés teria instituído a marca diferenciadora da circuncisão entre os judeus e com eles pretendera reavivar o monoteísmo egípcio, na transmissão de uma vida em "verdade e justiça" (Freud, 1939/2004a, p. 49). Este é o preâmbulo das análises de Freud das versões bíblicas, míticas e historiográficas sobre a origem e a vida de Moisés. Aqui nos interessam os eixos do mito e da história.

Devemos ressaltar, porém, que a história de Moisés foge à criação (die Erdichtung) das sagas arquetípicas sobre os heróis. E a pluralidade de contradições que dão um tom épico e engrandecedor a 
Moisés levam Freud a uma única certeza sobre seu acontecer-histórico (die Geschichte, Freud, 1939/2004a, p. 59): a de que Moisés sobreviveu a quaisquer que tenham sido as adversidades de sua infância e de seu nascimento.

Supondo que os mitos acrescentaram à biografia dessa personalidade arroubos fantásticos, eliminando lacunas e aspectos reprováveis, Freud (1939/2004a) admite que não poderia atravessar tantas dificuldades sem validar o mito como um texto que contém restos de verdade.

Como são superposições constantes e obscuras de conteúdos e sentidos, os mitos frustram a tentativa de obter com certeza um "núcleo de verdade histórica" (Freud, 1939/ 2004a, p. 15). Não é neste extremo da crítica ao mito onde Freud se situa, mas não desconsidera a avaliação de seus contemporâneos (Meyer, 1906; Sellin, 1922, citados por Freud, 1939/2004a).

No princípio das investigações do material reunido sobre Moisés, Freud se baseava na pesquisa histórica de seu tempo, mas a versão histórica feita à luz da psicanálise ganharia uma independência da historiografia, ao utilizar as incoerências das sagas para estabelecer verossimilhanças psicológicas sem comprovação material, mas que combinavam teorias e especulações nos mesmos argumentos. Eis aqui o ensejo para entendermos o passo metodológico freudiano, que trata o tempo e os fatos numa espé- 
cie de avesso da exígua cronologia historiográfica. Mas não deixamos de encontrar um texto rigoroso quanto às afirmações e aos modelos teóricos que traz. Podemos resumir esse tratamento peculiar com a ideia de que Freud extraiu algo da história ${ }^{3}$ (die Geschicbte), ao mesmo tempo em que introduziu nos seus elos conjecturas que sua clínica lhe permitia sustentar (Lo Bianco \& Araújo, 2007).

Voltando à marca da circuncisão: eis um detalhe fundamentado na história mas mal explicado por conclusões imprecisas e paradoxais sobre a religião monoteísta que figurou no Egito por volta de 1350 a. e. c. (Freud, 1939/2004a). Esse traço é encadeado na história do Judaísmo, como uma das heranças que Moisés - fugindo do império após a derrocada da dinastia monoteísta - levara à tribo semita.

Tal método explicitado no livro sobre Moisés (Freud, 1939/ 2004a), já se evidenciara há muito na técnica e na escrita de Freud: o tratamento inovador da história é seguido pela entrada do mito na teoria, viabilizando o prolongamento da sua argumentação no plano especulativo (Freud, 1913/2004c). Mas antes de expor sua versão histórica sobre as circunstâncias físicas e psicológicas dos primórdios da vida humana, ele sustentou um diálogo crítico, com seus contemporâneos (Frazer, 1922, Morgan, 1877 e Tylor, 1871 citados por Freud, 1913/2004c) sobre as origens do tabu do incesto e do totemismo.

As lacunas eram o que os especialistas abandonaram diante do fracasso em se obter uma explicação consistente para a origem da exogamia. Como psicanalista, Freud (1939/2004a) as recupera sem preenchê-las com dados científicos ou outras fontes. E apesar da impossibilidade de se reportar a uma história unindo passado e presente, ele estabelece uma continuidade necessária que inclui os hiatos no seu procedimento. Nessa inclusão dos hiatos, entendemos como Freud lidou com as descontinuidades com que todos os autores se deparam quando visam a recuperar uma perspectiva do passado através de uma sucessão cronológica dos acontecimentos.

Sustentando a distância entre suas proposições e a teoria especializada, é por meio deste écart que Freud (1913/2004c) coloca os hiatos na história como condição da historização, dando-lhe origem. Tal como será visto mais adiante, o elo entre as afirmações da história e da sociologia e as conjecturas psicanalíticas será a base do mito científico de "Totem e tabu" (Freud, 1913/2004c). 
Dado o que trouxemos, permanece a questão sobre se o mito fora um recurso para historicizar e preencher conhecimentos que as pesquisas historiográficas e etnológicas não puderam oferecer a Freud. Portanto, examinaremos o mito como ferramenta recolhida da antropologia, dos estudos mitológicos, acompanhando Freud (1900/2004d) desde a analogia entre a estrutura do mito e a formação do sonho.

\section{Os mitos: trivialidade ou sofisma? $^{4}$}

Antes de nos perguntarmos como o mito ganha espaço no método freudiano, traremos a definição que esse tópico, abandonado pela etnologia religiosa nas primeiras décadas do século XX, ganhou na conceituação estrutural de Lévi-Strauss (1955/1973).

Para o antropólogo (1955/1973), a verdade que o mito enuncia ultrapassa os diferentes códigos de suas versões; é preciso enxergar para além do código, e atingir a forma: um arcabouço esvaziado de significações nativas. $\mathrm{O}$ essencial no mito está na combinação entre seus termos, na capacidade de os múltiplos códigos se converterem em uma estrutura global (Lévi-Strauss, 1982/2008).

O mito combina, conciliando os homens, os deuses e a natureza empedernida numa cosmogonia circular e fechada, explicando a origem do mundo, o estado atual de uma sociedade, de seus membros, a função de seus rituais, normas e costumes (LéviStrauss, 1964/2004). A mitologia era um reflexo da estrutura da sociedade e da relação entre seus membros, sejam estas evidentes ou existam sentimentos hostis mascarados, por meio de uma combinatória, as inconsistências se dissolvem. A questão das contradições entre as variantes é solucionada no momento em que não se analisam mais os elementos isolados, mas a maneira como eles se combinam entre si (Lévi-Strauss, 1955/ 1973), tornando o mito uma narrativa harmoniosa e apaziguadora.

Revisando a errônea identificação do mito com a linguagem, LéviStrauss se vale de Saussure ${ }^{5}$ para afirmar que a história que o mito traz supera a sintaxe da língua onde foi produzida, ainda que não venha a prescindir deste terreno para ganhar sua universalidade e a possibilidade de ser compreendida por diferentes leitores e ouvintes.

Não nos deteremos em teorias lingüísticas, mas deve ser esclarecido que a suposição de dois níveis diferentes no discurso do mito, pertence à lógica estrutural, não é um efeito conhecido nas sociedades ditas frias (Lévi-Strauss, 1955/1973), onde o mito é um simbolismo que molda os fenômenos da realidade (mortes, desaparecimentos, seca, chuvas torrenciais etc).

É com o mito de Édipo que se exemplificam esses trâmites. Já que o 
que dispomos desse mito está dado apenas em textos literários, LéviStrauss (1955/1973) demonstra como ele pode ser manipulado, através de um método de experimentações sucessivas. Seus elementos são dispostos em cartões numerados que seguem a ordem da narrativa dentro de algumas condições necessárias. As unidades constitutivas do mito, chamadas de mitemas, são ilustradas por frases curtas e são as próprias relações entre os termos.

Cada mito precisa ser analisado de forma independente e "cada frase é inscrita numa ficha que traz um número correspondente a seu lugar na narrativa. Percebe-se, então, que cada cartão consiste na atribuição de um predicado a um sujeito. Ou melhor, cada grande unidade constitutiva tem a natureza de uma relação." (LéviStrauss, 1955/1973, p. 243).

Por fim, voltando às variantes de um mito, o seu grau de veracidade não impede a decomposição que conduz às invariantes, pois nenhuma das versões se acha mais próxima da verdade do mito. O mito é a soma de suas versões. Não há variantes mais verdadeiras e outras falsas; elas representam apenas muitos dos desdobramentos de uma estrutura (invariante) que se revela como a mesma (Lévi-Strauss, 1955/1973). 


\section{Onde estão os mitos?}

Independente do texto ou do tema oferecido ao leitor, encontramos uma complexidade no uso do mito por Freud, explicada pelas distintas acepções de mito advindas dos desdobramentos de suas elaborações (Freud, 1900/2004d, 1908/2004e, 1913/2004c, 1939/2004a). O mito se define por uma ficção cuja estrutura é análoga a dos sonhos; também acha na ficção do Édipo a ilustração da constituição histórica do aparato anímico; e como mito científico, encontramos uma teoria sobre a origem da cultura, pois a obra de Freud não se furta aos efeitos de enxertar o mito na práxis psicanalítica (Freud 1913/2004c, 1932/2004f). Assim veremos como se dá a depuração do mito como a cosmogonia dos antigos - o mais conhecido e menosprezado pelas teorias ditas científicas - (Frazer, 1922/1986; Tylor, 1871/2005 citados por Freud, 1913/2004c), até a sua conceituação psicanalítica.

Primeiramente, Freud recorreu à "psicomitologia" ou a "mitos endopsíquicos", assunto que ocupava sua atenção por volta de 1897, e definido ao amigo Fliess como resíduos da história, ilusões de pensamento, percepções internas ao aparelho psíquico que investem o universo, o futuro e o desconhecido, embora continuassem a ser construções humanas (Freud, 1913/2004c).

$\mathrm{Na}$ Traumdeutung, (1900/2004d) é assinalada uma similaridade entre os mitos e os sonhos considerando o mecanismo simbólico que os constitui, sem pretender igualar essas duas linguagens, já que o sonho se lhe apresentava como uma formação radicalmente nova. Freud $(1932 / 2004 \mathrm{~g})$ comenta que um fato precisaria sofrer muitas desfigurações para ganhar o formato fantástico de um mito, mas as transformações de conteúdo no seu oposto seriam tão acentuadas e frequentes como as que o analista acha na interpretação dos sonhos e na construção do histórico da infância, já que o sonho (e o infantil) é a substância do psiquismo, e o mito é uma estrutura que porta os vestígios das civilizações arcaicas.

Esse jogo de alternâncias entre seus elementos se assemelha com a maneira como Lévi-Strauss (1955/1973) analisava e comparava os mitos de diferentes culturas, invertendo os seus termos ou transpondo-os para um outro código. Quanto à "essência do mito", Freud não adere à esperança de atingir um significado primevo, pelo 
que fora criticado pelo antropólogo (1982/2008) anos depois.

Ao investir em comparações e reversões dos seus elementos, Freud (Lacan, 1954/1991) buscava elucidar o funcionamento e os efeitos dos mitos, pois se o que neles é puramente fantástico se entretece aos fatos, é preciso trabalhar com a história contada (Freud, 1939/2004a) para decantar o seu núcleo histórico.

Freud aferrava-se à função indispensável da história como a matériaprima das construções do analisante. O saber mítico não poderia servir como endosso de sua teoria e substituir a particularidade do trabalho do analisante de reconhecer as imagens do seu relato como próprias, quando se deve ignorar "tudo da teoria." (Lacan, 1952/2008, p. 18).

Pode parecer natural a comparação entre as figurações oníricas e míticas, mas em sua época Freud não dispunha do recurso à análise estrutural, e com os instrumentos que tinha pôde elaborar esboços aproximados do que Lévi-Strauss (1955/1973) formalizaria de um modo mais fácil e sofisticado. Em seu modelo de estrutura automatizada e autorregulada pela lógica de remissão entre os significantes não há espaço para a historicidade e para a singularidade do sujeito (Lévi-Strauss, 1955/1973). Lacan (1952/2008, 1954/1991) é quem atualizará as afirmações de Freud lendoas à luz do estruturalismo, dando um tratamento à história do sujeito que leva em conta o paradigma lévi- straussiano dos mitos, mas vai além dele.

\section{A etimologia do mito freudiano}

Vale lembrar os eixos em que enfrentamos a apropriação do mito em Freud: a relação dos mitos com a estrutura do sonho, com a ficção de Édipo e o mito científico da origem do sujeito e da cultura, em "Totem e tabu" (Freud, 1913/2004c). Antes de nos aprofundar neles, traremos indicações etimológicas, pois a origem e os significados dos vocábulos alemães escolhidos por Freud permitiu esboçar numa determinada organização nossa leitura do mito.

$\mathrm{Na}$ evocação dos mitos de nascimento dos heróis e dos mitos de abandono, Freud (1939/2004a) trabalha com as peripécias míticas de seus personagens no emprego do substantivo die Dichtung e as variações die Erdichtung e erdichten. Em função da riqueza desses termos, parece-nos oportuno investigá-los. O verbo erdicbten significa "inventar histórias (falsas)" (Kluge, 1989). Seu vasto radical dicht origina palavras como: Dichter, o poeta, e Gedicht, o poema ou uma poesia; num sentido mais abstrato e abrangente há die Dichtung podendo significar tanto atividade poética, quanto obra literária, prosa ou poesia. Mais interessante, contudo, é o sentido primitivo - e ainda corren- 
te - de dicbten. Ele também significa impermeabilizar, tapar, vedar, colocar camadas. É o movimento de se preparar um ambiente para a calefação (por isso die Dichtung pode significar simplesmente vedação). Isso mostra que em alemão o sentido originário de poesia e de criação literária estava estreitamente ligado à ideia de se arrumar por camadas um sentido, e nos lembra o texto das línguas latinas, apontando para um texere, isto é, o fazer tecido, construir sobrepondo ou entrelaçando (Kluge, 1989).

Como Erdichtung, ficção, podemos analisar o mito à luz dessas acepções do substantivo alemão: a invenção poética, as lendas e algo que se estrutura por camadas, onde podemos ainda reconhecer uma relação com a concepção estruturalista (LéviStrauss, 1955/1973): essa teia lógica tem um significado intrínseco à sua urdidura e gera uma rede de significados sob a forma de uma narrativa.

\section{O mito na pré-história das crianças e da humanidade}

Quanto ao mito de Édipo, essa saga das vicissitudes do sujeito Lacan, (1954/1991), tem em Freud (1908/ 2004e, pp. 75-6) o estatuto de complexo nuclear das neuroses. Ao exprimir as relações fundamentais da criança com os pais ou com os que cuidam dela, a trama edípica dá conta dos percalços da descoberta da diferença 
sexual e nas investigações sobre a origem dos bebês (Freud, 1908/2004e).

Desde "A interpretação dos sonhos" (Freud, 1900/2004d), os desejos e conflitos edípicos, isto é, as fantasias sexuais que investem a figura dos pais como a forma primeira do desejo infantil, ocupam uma posição de destaque junto à primeira formulação da estrutura do aparato anímico. Freud $(1908 / 2004$ e) refere essa rede de situações a um estágio: o romance familiar dos neuróticos, onde reside a origem de toda a ficção. Ao tratar do mito dentro de uma discussão sobre os acontecimentos da vida infantil, Freud afirma que nas fantasias infantis a que a análise remonta é onde se acha o meio para se entender o mito.

Em decorrência de experiências como o nascimento de um irmão, os castigos, os ciúmes ou as rivalidades da sua própria relação com os outros, é este "o pano onde se talham" (Freud, 1908/2004, p. 218) histórias míticas (die Dichtung), nas quais a criança inventa uma outra origem para si mesma, colocando-se como herdeira de pais nobres. A fantasia neurótica e infantil, diz-nos Freud (1908/2004e), atinge o nível de uma produção mítica, de uma atividade criadora análoga às histórias dos mitos coletivos, próxima das bases da invenção poética e literária, reencenando o tempo mítico da infância e expressando o lamento por uma idade feliz e extinta.

O Édipo então fornece a Freud (1908/2004e) a substância do infan- til, a ficção fundadora do psiquismo sob a ótica de um conflito necessário, interno às relações e aos sentimentos ambivalentes que esse complexo manifesta. Pois a moral dessa tragédia, seus desejos incestuosos e agressivos, possibilitaram a Freud validar sua teoria com dados de sua autoanálise: "Eu mesmo vivo tudo o que pude observar, como ouvinte, nos meus pacientes.... Descobri em mim, como em toda parte, sentimentos de amor por minha mãe e de ciúmes por meu pai." (Freud, 1956[1897]/1986, carta 70).

A universalidade afirmada sobre o Édipo, muitas vezes criticada como falaciosa, pertence "à atitude afetiva na relação com a família" (Freud, 1919/2004h, p. 257) ao domínio das observações de Freud e das confirmações de uma estrutura de relações que ele via se repetir nos casos de que tratou. A história remontada a uma situação conflitual e incestuosa permite a criação do primeiro "mito individual", como a cena inaugural e inconsciente, acessada apenas pela exemplificação mítica.

Até os últimos acréscimos aos "Três ensaios de teoria sexual" (Freud, 1905/2004i), o Édipo se desprende de sua primeira concepção, mais atrelada ao texere da tragédia grega e assume uma função mais próxima da experiência cotidiana do sujeito. Freud (1932/2004f) descreve quase com minúcias a passagem do menino e da menina e a diferença nos destinos com que cada gênero sai desta experiência. A saída do Édipo or- 
ganiza o campo pulsional do sujeito e determina também a escolha dos objetos de amor. A estrutura de sua ficção mítica se transforma, atravessada pela teorização e pela escuta clínica, na descrição freudiana do infantil e que se atualiza na transferência com o analista. A tragédia antiga e de repercussão universal se encarna como realidade psíquica, como mito - história - atual e individual.

Apesar do uso de Édipo estar presente desde cedo, o mito só se consolida como recurso teórico na psicanálise com o "mito científico da família primordial" (Freud, 1913/ 2004c). A alcunha dada pelo próprio Freud resume sua construção científica que mescla hipóteses históricas e especulações sobre os primórdios da vida humana e do preâmbulo das organizações sociais vindouras. Esta teoria será um mito fundador na sua obra, pois narra e refaz - da atualidade para o passado - o percurso do sujeito e da sociedade amarrados numa mesma história.

Nesta época Freud volta a afirmar um rompimento com a cisão entre uma psicologia do indivíduo e uma psicologia social ao estabelecer uma conexão entre as experiências do neurótico e as formas de pensamento mágicas da cultura, da religião e das lendas primitivas. "Totem e tabu" (Freud, 1913/2004c), tão polêmico quanto só o seria, como vimos, "Moisés e o monoteísmo" (Freud, 1939/2004a), contém uma história considerada impossível por todos os 
estudiosos do campo que a leram. Pinçaremos suas questões mais valiosas para nossa argumentação.

$\mathrm{Na}$ recapitulação das teorias sobre os eventos necessários à instituição do tabu do incesto, Freud (1913/2004c) lê o desenvolvimento cultural através das "formas singulares da neurose" (p. 78), para em seguida fornecer sua versão sobre os fatos. A asserção de que a neurose conserva o mesmo funcionamento das relações dos homens primitivos entre si e com a natureza merece uma reflexão particular mas basta-nos aqui identificar essa inovação e apontá-la como o norte do método de Freud.

Voltando ao foco do artigo, a versão histórico-mitológica de Freud se equilibra sobre os achados de três historiadores: (Darwin, 1871; Atkinson, 1903; Robertson Smith, 1894, citados por Freud, 1913/2004c). Em Darwin, nosso autor se interessa pela analogia entre a vida social de um grupo de primatas e a organização dos primeiros homens. As primeiras sociedades humanas se organizavam, segundo o biólogo, em pequenas hordas governadas por chefes que se apoderavam das mulheres e impediam que os outros homens tivessem acesso a elas, obrigando-os a buscarem companheiras em outros clãs.

De Atkinson (1903, citado por Freud, 1913/2004c), vem a ideia de que os homens banidos pela irascibilidade do chefe partiam e fundavam outras comunidades, o que em si já explicaria a exogamia como uma necessidade e um fato social. Desse modo, Darwin (1871, citado por Freud, 1913/2004c) e Atkinson (1903, citado por Freud, 1913/2004c), ao contrário dos autores mais nobres no campo, seus contemporâneos, postulavam que o totemismo é uma conseqüência da exogamia em que são lançados os primeiros homens pelo chefe da horda: o que para Freud sempre foi importante não abandonar.

Faltava encadear nesta constelação a instituição totêmica e para tanto Freud lança mão das hipóteses de Robertson Smith (1894, citado por Freud, 1913/2004c) sobre o banquete e o animal totêmicos como os primórdios do sistema de totens. Para o professor de teologia, teriam existido animais sacrificados e devorados em festividades e ritos anuais. Freud se valeu da exceção à proibição que cercava o animal sagrado no cotidiano como uma particularidade essencial das sociedades totêmicas, propondo-nos a alegoria de uma festa sacrificial que refaz as circunstâncias mentais ambivalentes de uma tribo que sacrificava a cada ano seu animal protetor. 
$\mathrm{Na}$ horda de Darwin não havia espaço para o surgimento do totemismo, mas um estado de coisas avesso ao de qualquer sociedade conhecida: uma liga de homens submetidos às mesmas leis do líder tirânico. Para conceber uma relação entre a cultura de seu tempo e uma sociedade que já apresentasse os rudimentos da exogamia, Freud (1913/2004c) precisava colocar a conjectura darwiniana no passado primordial, como a origem dos sistemas sociais. E para que a dissolução do clã, Freud (1913/2004c) presumiu que os sentimentos ambivalentes da neurose também existiram entre esses jovens, o que os teria levado a um crime contra seu chefe. A afeição, porém, em que o tinham levou-os ao arrependimento e ao sentimento de culpa (Robertson Smith, 1894, citado por Freud, 1913/ 2004c).

Se esta articulação no princípio soava absurda, também possuía (Freud, 1913/2004c) a vantagem de integrar eventos afastados no tempo em uma versão, tida como equivocada do ponto de vista acadêmico, (Lévi-Strauss, 1985/2007), que sob a ótica psicanalítica das neuroses pode ser tomada como histórica. Esse mito fundador apresenta as teses de Atkinson, as do livro de Smith e a hipótese das hordas de Darwin ordenadas historicamente à luz da psicanálise como uma teoria que não constava na antropologia de então.

\section{Nos mitos, a origem de um método}

Com o mito psicanalítico de "Totem e tabu", Freud (1913/2004c; Lacan, 1954/1991) dá uma origem ao sujeito e a suas relações com o outro, desorganizando nossas ilusões e nos dando ficções legítimas, lúcidas e tristes como as das ciências especializadas (Freud, 1937/2004j), sobre como o mundo teria necessariamente começado. Lévi-Strauss (1985/2007), em muitas oportunidades, criticaria Freud por ter passado dos mitos aos fatos, sobretudo em "Totem e tabu" (Freud, 1913/2004c), e ter depreendido eventos incomprovados à sua pré-história da cultura.

A passagem de Freud da mitologia ao fazer científico caracteriza o seu procedimento clínico-teórico: uma mitologia científica que traz coincidências entre a vida humana arcaica e as configurações da neurose moderna. Por outro lado, em lugar de reconhecer uma cumplicidade entre os homens e a natureza, a mesma que é evocada na circularidade dos mitos sociais (Lévi-Strauss, 1955/1973) que domesticam a inclemência dos fenômenos naturais, Freud (1933/2004l), constrói uma teoria mitológica que expõe a descontinuidade irremediável entre a ordem humana e a ordem da natureza.

Lidando com o relato do analisante como o mito que estrutura a verdade na análise e amparado pela 
noção de construção como o trabalho feito por analista e analisante, Freud trata cada caso como uma história única onde ficções e fatos se sobrepõem, confundindo-se. Para tanto, foi necessário ir além da comprovação empírica e da justificativa cronológica (Freud, 1918/2004b) e se fiar na maneira como o sujeito se posiciona dentro do que conta ao analista e qual o lugar que toma na história que conta.

Assim, Freud funda um núcleo de verdade histórica que explica a gênese da cultura, núcleo resultante de um trabalho de construção. Diante de enigmas e impasses clínicos, os mitos de Freud são uma conjectura teórica na qual se entrecruzam a observação clínica, a teoria metapsicológica e a especulação própria ao mito. A importância de recuperar a crítica que Freud fez de sua função na cultura e na vida anímica, reside na verdade que se denuncia no seu relato, permitindo-nos derivar aproximações e distanciamentos entre o relato mítico coletivo e os mitos individuais que Freud escutava. Os dados da experiência analítica não podiam ser verificados pela historiografia ou pelas tradições etnológicas e antropológicas nas quais Freud submerge para depois romper com seus cânones.

O método de Freud nos traz uma mitologia tempestuosa e pessimista como condição única de reinvenção de um sujeito fruto do mal estar e do não-apaziguamento gerados pela falência das tradições e dos mitos e re-

40 Estilos da Clínica, 2012, 17(1), 26-43 
ligiões e pelas limitações da ciência. O que importava a Freud e o que deve interessar a todo analista é o peso das invariantes dos mitos individuais de cujo desmonte ou de cuja construção ele é parte. O que causa sofrimento, resistindo à historização, o que sobra sem domesticação mostra como Freud, mesmo tendo se servido da mitologia, encontrou em sua época, mitos e elementos de uma clínica que escapam à conciliação e ao final feliz dos mitos coletivos e dos contos de fadas.

MYTH AND TRUTH IN FREUD: HOW TO BUILD A CLINIC

\section{Abstract}

Our proposal begins trying to circumscribe the definition of myth to Freud, showing their fruitful theorizing about the structure of the sagas for analytic praxis. The light, above all, Moses and Monotheism and Totem and Taboo followed our goal of showing that the myth occupies a prominent place in the psychoanalytic field, and the ways of Frend's work led us to the conclusion that the founder of psychoanalysis ends by recognizing the pattern of mythical stories - reworked by psychoanalysis - an intersection with its own conception of historical truth.

Index terms: myth; psychoanalysis; anthropology; historical truth.

\section{MITO Y VERDAD EN FREUD: COMO SE CONSTRUYE UNA CLÍNICA}

\section{RESUMEN}

Nuestra propuesta comienza tratando de circunscribir la definición de mito a Freud, mostrando su fructifera teorización acerca de la estructura de las sagas en la praxis analítica. Especialmente a la luz de Moisés y la religión monoteísta y Tótem y Tabú, seguimos nuestro objetivo de mostrar que el mito ocupa un lugar destacado en el campo psicoanalitico, y las formas de la obra de Freud nos han llevado a la conclusión de que el fundador del psicoanálisis termina por reconocer el patrón de historias míticas - reelaborado por el psicoanálisis - en una intersección con su propia concepción de la verdad histórica.

Palabras clave: mito; psicoanálisis; antropología; verdad histórica.

\section{REFERÊNCIAS}

Bloch, M. (2001). Apologia da história. Rio de Janeiro: Jorge Zahar Editor. (Trabalho original publicado em 1949)

Carr, E. H. (2002). O que é história? Rio de Janeiro: Paz e Terra. (Trabalho original publicado em 1961)

Freud, S. (1986). Cartas 70 y 71. In S. Freud, Obras completas (J. Etcheverry, trad., Vol. 1, pp. 302-307). Buenos Aires: Amorrortu. (Trabalho original publicado em 1956) 
Freud, S. (1991). Der Mann Moses und die monotheistische Religion. In S. Freud. GesammelteWerke, Werkeaus den jabren 1932 1939. Frankfurt: S. Fischer.

Freud, S. (2004a). Moisés y la religión monoteísta. In S. Freud, Obras completas (J. Etcheverryt. trad., Vol. 23, pp. 1-132). Buenos Aires: Amorrortu. (Trabalho original publicado em 1939)

Freud, S. (2004b). De la historia de una neurosis infantil. In S. Freud, Obras completas (J. Etcheverry, trad., Vol. 17I, pp. 1111). Buenos Aires: Amorrortu. (Trabalho original publicado em 1918)

Freud, S. (2004c). Tóten y tabú. In S. Freud, Obras completas (J. Etcheverry, trad., Vol. 13, pp. 1-164 ). Buenos Aires: Amorrortu. (Trabalho original publicado em 1913)

Freud, S. (2004d). El trabajo del sueño. In S. Freud, Obras completes (J. Etcheverry, trad., Vol. 4, pp. 285-343). Buenos Aires: Amorrortu. (Trabalho original publicado em 1900)

Freud, S. (2004e). La novela familiar de los neuróticos. In S. Freud, Obras completes (J. Etcheverry, trad., Vol. 9, pp. 213-220). Buenos Aires: Amorrortu. (Trabalho original publicado em 1908)

Freud, S. (2004f). Angustia y vida pulsional In S. Freud, Obras completas (J. Etcheverry, trad., Vol. 22, pp. 75-103). Buenos Aires: Amorrortu. (Trabalho original publicado em 1932)

Freud, S. (2004g). Sobre la conquista del fuego. In S. Freud, Obras completas (J. Etcheverry, trad., Vol. 22, pp. 169-178). Buenos Aires: Amorrortu. (Trabalho original publicado em 1932)

Freud, S. (2004h). El ominoso. In S. Freud, Obras completas (J. Etcheverry, trad., Vol. 27, pp. 219-251). Buenos Aires: Amorrortu. (Trabalho original publicado em 1919)

Freud, S. (2004i). Tres ensayos de teoría sexual. In S. Freud, Obras completes (J. Etcheverry, trad., Vol. 7, pp. 110-222). Buenos Aires: Amorrortu. (Trabalho original publicado em 1905)
Freud, S. (2004j). Construcciones en el análisis. In S. Freud, Obras completas (J. Etcheverry, trad., Vol. 23, pp. 255-270). Buenos Aires: Amorrortu. (Trabalho original publicado em 1937)

Freud, S. (2004l). En torno de una cosmovisión. In S. Freud, Obras completes (J. Etcheverry, trad., Vol. 22, pp. 146-168). Buenos Aires: Amorrortu. (Trabalho original publicado em 1933)

Kluge, F. (1989). Etymologisches Wörterbuch der deutschen Sprache. Berlin: Walter Gruyter.

Lacan, J. (1966). Fonction et champ de la parole et du langage en psychanalyse. In J. Lacan, Écrits 1, (pp. 111-208). Paris: Seuil.

Lacan, J. (1991). Oedipe, Moïse et le père de la horde. In Le séminaire, livre 17: l'envers de la psychanalyse (pp. 117-135). Paris: Seuil. (Trabalho original publicado em 1954)

Lacan, J. (2008). O mito individual do neurótico. (C. Berliner, trad.). Rio de Janeiro: Jorge Zahar. (Trabalho original publicado em 1952)

Lemérer, B. (1997). Les deux Moïse de Frend (1914-1939): Freud et Moïse écriture du père 1. Paris: Érès.

Le Goff (2001). Prefácio. In M. Bloch. Apologia da história (pp. 95-96). Rio de Janeiro: Jorge Zahar.

Lévi-Strauss, C. (1949). Les structures élémentaires de la parenté. Paris: PUF.

Lévi-Strauss, C. (1973). A estrutura dos mitos. In C. Lévi-Strauss, Antropologia estrutural (C.S. Katz \& E. Pires, trad, pp. 237 265). Rio de Janeiro: Biblioteca Tempo Universitário, tempo brasileiro. (Trabalho original publicado em 1955)

Lévi-Strauss, C. (2004). O cru e o cozido. Mitológicas I. São Paulo: Cosac \& Naify. (Trabalho original publicado em 1964)

Lévi-Strauss, C. (2008). "Toten et tabou" version Jivaro. In C. Lévi-Strauss, La potière jalouse (pp. 1213-1231). Paris: La Pléiade. (Trabalho original publicado em 1982)

Lo Bianco, A. C. \& Araújo, A. V. (2007). A construção do histórico em Freud. Revista do Departamento de Psicologia - UFF, 19(2), 359-368. 


\section{NOTAS}

1 Não pretendemos dissolver as fronteiras entre as obras de Ranke e de Langlois e Seignobos demarcadas por particularidades culturais e individuais. Aqui contaremos porém com os pontos de aproximação de seus textos que nos permitem reconhecê-los como representantes da vertente positivista.

2 Remetemos o leitor às obras que é história? e Apologia da história para esclarecimentos sobre a tradição positivista/empirista debatida e criticada à luz da reflexão de Carr e Bloch.

3 “al hecho que hemos extraído de la história de la religión judia o, si se quiere, que hemos introducido en ella". (Freud, 2004, p. 119).

4 "Para compreender o que é um mito, não temos, pois, outra escolha senão entre a trivialidade e o sofisma?" (Lévi-Strauss, 1955/1973, p. 238)

5 Saussurre, F. Cours de linguistique générale. Paris, Payot, 1915. Foi desta obra póstuma de Saussure que Lévi-Strauss tomou as dicotomias: significante X significado, e diacronia $\mathrm{X}$ sincronia, empregando-as na análise dos mitos. Neste artigo, trabalharemos apenas com a primeira delas, pois ainda que os planos de um mito realizem os eixos da sincronia e da diacronia, a sua discussão envolve a apresentação do tema da repetição e do tempo míticos, assuntos que, ainda que sejam muito importantes na antropologia e na psicanálise, extrapolam a nossa proposta atual de destacar os aspectos básicos da análise estrutural, que permitam mostrar as diferenças e os pontos de aproximação entre esta e a apropriação freudiana do mito.

6 Esta expressão "mito individual" foi empregada por Lévi-Strauss antes mesmo do artigo A estrutura dos mitos (1955/1973), mas foi retomada por Lacan em O mito individual do neurótico (1952/2004). 